\title{
Awareness and practice about the association between periodontal diseases and diabetes mellitus: a cross-sectional study in Western Saudi Arabia among health care providers
}

This article was published in the following Dove Press journal:

Journal of Multidisciplinary Healthcare

\author{
Maha A Bahammam \\ Department of Periodontology, \\ Faculty of Dentistry, King Abdulaziz \\ University, Jeddah, Saudi Arabia
}

Correspondence: Maha A Bahammam Department of Periodontology, Faculty of Dentistry, King Abdulaziz University, PO Box 80209, Jeddah 21589, Saudi Arabia Tel +966505303227

Fax +966I264033I6

Email mbahammam@kau.edu.sa
Purpose: This study aims to assess the awareness and practices of dental and medical practitioners regarding the bidirectional relationship between periodontal diseases and diabetes mellitus. Patients and methods: A cross-sectional survey of randomly selected dentists and physicians practicing in Jeddah. Participants were asked several questions concerning their awareness and practices on periodontal complications, and the bidirectional link between periodontal diseases and diabetes mellitus (DM).

Results: A total of 560 general practitioners (284 dentists and 276 physicians) participated in the study. There were no significant differences between the two groups regarding any sociodemographic characteristics. Overall, the awareness of all participants was low in all aspects. Moreover, dentists' awareness and practices were significantly better than physicians as majority of the questions were about the association between periodontal diseases and DM.

Conclusion: The awareness and practices about the link between periodontal diseases and DM should be improved among dental and medical practitioners to effectively prevent and control periodontal diseases and DM.

Keywords: diabetes mellitus, oral health, periodontal complications, periodontal diseases

\section{Introduction}

Approximately 285 million people globally are afflicted with diabetes, and as such the rate of incidence is expected to show a steady increase over the years. It has been documented in several studies pertaining to the conduction of global surveys that diabetes presents as a major public health care concern across every race, having an epidemic spread and a rapidly increasing prevalence. ${ }^{1-7}$ With regard to Saudi Arabia, it was noted that the overall prevalence of diabetes mellitus (DM) for both males and females residing in rural and urban communities was $23.7 \%$, with percentages of $26.2 \%$ and $21.5 \%$ for males and females, respectively. ${ }^{8}$

It is also well established that diabetes is a risk factor for periodontal diseases, and there is a bidirectional relationship between DM and the onset of periodontal diseases. ${ }^{9,10}$ Certain studies have indicated a greater susceptibility of diabetic patients toward severe forms of periodontal destruction. These studies further highlighted that effective treatment of periodontitis was strongly linked to enhancements in glycemic control. ${ }^{1-13}$ However, there is a lack of awareness among dental and medical 
practitioners with regard to the strong association between DM and the onset of periodontal diseases among the diabetic population. ${ }^{14}$ Owing to this, there is a corresponding lack of awareness among diabetic patients in this regard, which thus has an adverse effect on their oral health and overall quality of life.

As discussed earlier, there is an ever-increasing prevalence of DM among the Saudi population. Subsequently, it follows that such increased prevalence of DM would be associated with an increasing prevalence of periodontal diseases among the Saudi diabetic population. However, there have been no studies conducted to determine the levels of awareness among dental and medical practitioners within Saudi Arabia regarding the association between DM and periodontal diseases. A recent publication indicated that none of the investigated patients had ever been advised by their physicians to brush their teeth and that only 5.2\% had been recommended by a physician to see their dentist regularly. ${ }^{15}$ These results indicated a huge negligence among physicians related to the influence of periodontal health on glycemic control of diabetic patients. Therefore, there was an urgent need to investigate clinicians' awareness and practices pertaining to this relevant issue, so that educational awareness programs and an integrated practice structure may be devised for the prevention and effective management of periodontal diseases in Saudi diabetic patients.

This study was conducted with the aim of investigating the levels of awareness and practices of dental and medical practitioners with regard to the effects of DM on periodontal health within the Saudi diabetic population. It is to be noted that this is the first study that has been conducted with regard to investigating the awareness levels among dental and medical practitioners that operate in Saudi Arabia.

\section{Materials and methods}

This was a cross-sectional descriptive survey of 800 randomly selected dentists and physicians, working in different public and private health care services in Jeddah, Saudi Arabia. The study was conducted from November 2016 to November 2017. The participants of the study were investigated through the use of an anonymous, self-administered, and structured questionnaire that was reviewed for appropriate wording by experienced academics at King Abdulaziz University. Subsequently, the questionnaire was piloted on 30 patients to determine the time required and readability.

Prior to the commencement of the project, the study protocol was approved by Research Ethics Committee of King Abdulaziz University Faculty of Dentistry. Ethical approval (number 005-16) was accepted by the committee to take verbal consent from the participants, and the study was conducted in accordance with the principles of the Declaration of Helsinki. This study made use of voluntary participation, where informed verbal consent was obtained from each participant prior to their contribution. Before the initiation of the investigation, a brief explanation of the project and its focal objectives were provided to the participants. The questionnaire was validated by the Research Ethics Committee of King Abdulaziz University Faculty of Dentistry.

Participants were then asked to complete four parts of a questionnaire. The first part recorded the demographic characteristics of participants including age, sex, level of education, specialties, and number of years in practice. In the second part, participants were asked questions to determine their awareness of several periodontal complications that diabetic patients are more susceptible to. These complications were inclusive of gingival inflammation, gingival bleeding, gingival recession, alveolar bone resorption, tooth loss, tooth mobility, and periodontal abscess.

The third part of the questionnaire concerned the practices of participants regarding oral health advice for patients with diabetes including the importance of regular dental check-ups, the necessity of more frequent dental check-ups for patients with poorly controlled diabetes, and the need of more frequent dental scaling than others without diabetes. In the fourth and final part of the questionnaire, all participants were requested to report their awareness about diabetes and its effect on periodontal health and whether a periodontal status might affect the metabolic control of diabetic patients. For all of the questions in the second, third, and fourth sections, participants were given the choice of "yes," "no," or "I do not know."

Data was entered into the statistical package SPSS 22.00 for windows (IBM Corporation, Armonk, NY, USA). To simplify the results, some responses were grouped as correct and incorrect answers. Descriptive statistics in the form of frequency distribution were performed for all study variables. A chi-squared test was calculated to detect significant associations among categorical variables. A binary logistic regression analysis was performed to examine which factors were significant in a multivariate analysis after adjusting for confounding among effects. The regression model used the dependent variable awareness score calculated in the following manner: items scores were summed up and categorized into good-fair ( $\geq$ median) and poor $<$ median. Independent variables entered in the model were age, gender, level of education specialty, and profession (dentist or physician). Statistical significance was set at $P<0.05$. 


\section{Results}

A total of 800 health care providers were contacted to participate. Only 560 health care providers (284 dentists and 276 physicians) responded, leading to a response rate of $70 \%$. The mean age for dentists was 32.78 years, SD 7.54. The mean age of physicians was 32.03 years, SD 7.76. Table 1 shows the demographic characteristics of participating health care providers. No statistical differences were detected between dentists and physicians regarding any demographic characteristic studied (age, gender, level of education, and years of experience). Table 2 shows participants' awareness to different periodontal complications associated with DM. Overall, the dentists reported better awareness levels than the physicians in the different items of periodontal complication except for gingival inflammation which showed no statistically significant difference in the awareness level $(P<0.05)$.

The comparison between participants' regarding their self-reported practices to patients diagnosed with diabetes

Table I Demographic characteristics of participants

\begin{tabular}{|c|c|c|c|c|}
\hline Characteristics & $\begin{array}{l}\text { Dentist, } \\
\text { N (\%) }\end{array}$ & $\begin{array}{l}\text { Physician, } \\
\text { N (\%) }\end{array}$ & $\chi^{2}$ & $P$-value \\
\hline \multicolumn{4}{|l|}{ Age (years) } & \multirow[t]{5}{*}{0.439} \\
\hline$\leq 30$ & 99 (34.9) & $108(39.1)$ & & \\
\hline$>30-40$ & $143(50.4 \%)$ & $120(43.5)$ & 2.706 & \\
\hline$>40-50$ & $32(I I .3$ & $36(13.0)$ & & \\
\hline$>50$ & $10(3.5)$ & $12(4.3)$ & & \\
\hline \multicolumn{4}{|l|}{ Gender } & \multirow[t]{3}{*}{0.077} \\
\hline Male & $197(70.1)$ & $214(76.7)$ & 3.12 & \\
\hline Female & $84(29.9)$ & $65(23.3)$ & & \\
\hline \multicolumn{4}{|l|}{ Levels of education } & \multirow[t]{3}{*}{0.056} \\
\hline General practitioners & $147(5 \mid .8)$ & $165(59.8)$ & 3.65 & \\
\hline Specialists & $137(48.2)$ & III (40.2) & & \\
\hline \multicolumn{4}{|l|}{ Years of experience } & \multirow[t]{3}{*}{0.256} \\
\hline$<5$ years & $198(69.7)$ & $180(65.2)$ & 1.293 & \\
\hline$\geq 5$ years & $86(30.3)$ & $96(34.8)$ & & \\
\hline
\end{tabular}

Table 2 Comparison between dentists and physicians regarding their awareness of periodontal complications

\begin{tabular}{|l|l|l|l|l|}
\hline \multirow{2}{*}{$\begin{array}{l}\text { Periodontal } \\
\text { complications }\end{array}$} & \multicolumn{2}{|l|}{ Yes } & $\chi^{2}$ & P-value \\
\cline { 2 - 5 } & $\begin{array}{l}\text { Dentist, } \\
\text { N (\%) }\end{array}$ & $\begin{array}{l}\text { Physician, } \\
\text { N (\%) }\end{array}$ & & \\
\hline Gingival inflammation & $253(90.0)$ & $259(92.5)$ & $5 I .058$ & $0.30 I$ \\
\hline Gingival bleeding & $237(83.5)$ & $168(60.9)$ & $5 I .688$ & $<0.00 I^{\mathrm{a}}$ \\
\hline Gingival recession & $228(80.3)$ & $144(52.2)$ & $7 I .40 I$ & $<0.00 I^{\mathrm{a}}$ \\
\hline $\begin{array}{l}\text { Alveolar bone } \\
\text { resorption }\end{array}$ & $269(94.7)$ & $180(65.2)$ & $8 I .607$ & $<0.00 \mathrm{I}^{\mathrm{a}}$ \\
\hline Tooth loss & $256(90 . \mathrm{I})$ & $216(78.3)$ & 54.137 & $<0.00 \mathrm{I}^{\mathrm{a}}$ \\
\hline Tooth mobility & $27 \mathrm{I}(95.4)$ & $192(69.6)$ & 68.997 & $<0.00 \mathrm{I}^{\mathrm{a}}$ \\
\hline Periodontal abscess & $2 \mathrm{II}(74.3)$ & $240(87.0)$ & 17.860 & $<0.00 \mathrm{I}^{\mathrm{a}}$ \\
\hline
\end{tabular}

Note: aSignificance level at $P<0.05$. are presented in Table 3. It was seen that the majority of participants (98.9\% dentists and all physicians $100 \%)$ instructed their diabetic patients to have regular dental check-ups, especially for patients with poorly controlled diabetes (dentists 93\% and physicians $82.6 \%)(P<0.05)$. Dentist responses were noted to be significantly higher than physician responses. However, the response was noted to be generally low with regard to professional dental scaling. Nevertheless, as compared to physicians, a significantly higher number of dentists provided more frequent dental scaling to diabetic patients than individuals without diabetes (diabetes $63 \%$, physicians $51.8 \%)(P<0.05)$. It was noted that there was a low level of awareness regarding the administration of prophylactic antibiotics to diabetic patients. However, this awareness level was still noted to be at a higher level for dentists as compared to the physicians (dentists $33.1 \%$, physicians 30.4\%) $(P<0.005)$.

Table 4 presents dentists' and physicians' awareness regarding the association between periodontal diseases and DM. Both dentists and physicians were aware that diabetes affects periodontal health, and there was no significant difference between both groups (dentists $96.8 \%$ and physicians $95.7 \%$ ). However, the dentists were significantly more aware than physicians that there is a bidirectional relation between periodontal disease and diabetes (dentists $83.1 \%$ and physicians $65.2 \%)(P<0.05)$. Moreover, dentists were significantly more aware of the importance of educating patients regarding their periodontal health than physicians (dentists $97.5 \%$ and physicians 56.5\%) $(P<0.05)$. However, more than one-third of the participants were not aware of the effect of periodontal diseases on metabolic control and that the treatment of periodontal disease would result in the improvement of metabolic control in diabetic patients. There was no statistically significant difference between both groups.

Table 5 presents the binary logistic regression analysis of factors related to participant awareness and practices. Age and type of profession were the only significant variables associated with awareness levels. It was noted that older participants were three times less aware of periodontal complications than younger participants. Furthermore, the physicians were almost eight times less aware of periodontal complications than dentists (odds ratio $[\mathrm{OR}]=7.82 ; 95 \% \mathrm{CI}$ : 5.21-11.79; $P<0.001)$. Poor practices were noted to be more likely among older physicians and general practitioners. Furthermore, poor practices toward diabetic patients were noted to be more likely among older physicians compared to dentists $(\mathrm{OR}=1.52 ; 95 \% \mathrm{CI}$ : $1.07-2.17 ; P=0.020)$. Moreover, poor practices were noted to be more likely among general practitioners as opposed to specialists $(\mathrm{OR}=0.64$; 
Table 3 Comparison between dentists and physicians regarding their self-reported practices for patients with DM

\begin{tabular}{|c|c|c|c|c|c|c|}
\hline \multirow[t]{2}{*}{ Statements } & \multicolumn{2}{|c|}{ Dentists' responses } & \multicolumn{2}{|c|}{ Physicians' responses } & \multirow[t]{2}{*}{$\chi^{2}$} & \multirow[t]{2}{*}{$P$-value } \\
\hline & Yes, N (\%) & No, $\mathbf{N}(\%)$ & Yes, N (\%) & No, $\mathbf{N}(\%)$ & & \\
\hline I instruct diabetic patients to have regular dental check-ups & $281(98.9)$ & $3(I . I)$ & $276(100)$ & $0(0)$ & 2.931 & 0.087 \\
\hline $\begin{array}{l}\text { I instruct poorly controlled diabetic patients to have more } \\
\text { frequent dental check-ups }\end{array}$ & $264(93.0)$ & $20(7.0)$ & $228(82.6)$ & $48(17.3)$ & 40.528 & $<0.00 I^{\mathrm{a}}$ \\
\hline $\begin{array}{l}\text { I do not give diabetic patients more frequent dental scaling than } \\
\text { individuals without diabetes }\end{array}$ & $179(63.0)$ & $105(37.0)$ & $144(52.2)$ & $132(51.8)$ & 31.169 & $<0.00 I^{a}$ \\
\hline
\end{tabular}

Note: asignificance level at $P<0.05$.

Abbreviation: DM, diabetes mellitus.

Table 4 Comparison of dentists and physicians regarding their awareness of the association between DM and periodontal health

\begin{tabular}{|c|c|c|c|c|c|c|}
\hline \multirow[t]{2}{*}{ Items } & \multicolumn{2}{|c|}{ Dentists' responses } & \multicolumn{2}{|c|}{ Physicians' responses } & \multirow[t]{2}{*}{$\chi^{2}$} & \multirow[t]{2}{*}{$P$-value } \\
\hline & Yes, N (\%) & No, $\mathbf{N}(\%)$ & Yes, N (\%) & No, N (\%) & & \\
\hline Diabetes affects periodontal health & $275(96.8)$ & $9(3.2)$ & $264(95.7)$ & $12(4.3)$ & 17.421 & 0.463 \\
\hline $\begin{array}{l}\text { Periodontal conditions would affect the metabolic control } \\
\text { of diabetes }\end{array}$ & $192(67.6)$ & $92(32.4)$ & $204(73.9)$ & $72(26.0)$ & 22.034 & 0.101 \\
\hline $\begin{array}{l}\text { Treating your periodontal disease would improve the } \\
\text { metabolic control of the diabetic patients }\end{array}$ & $193(68.0)$ & $91(32)$ & 204 (73.9) & $72(26.1)$ & 6.085 & 0.121 \\
\hline $\begin{array}{l}\text { There is a bidirectional relationship between periodontal } \\
\text { disease and diabetes }\end{array}$ & $236(83.1)$ & $48(16.9)$ & $180(65.2)$ & $96(34.7)$ & 51.004 & $<0.00 I^{\mathrm{a}}$ \\
\hline $\begin{array}{l}\text { I do give my patients instruction about their periodontal } \\
\text { health }\end{array}$ & $277(97.5)$ & $7(2.5)$ & $156(56.5)$ & $120(43.5)$ & 145.244 & $<0.00 I^{a}$ \\
\hline
\end{tabular}

Note: ${ }^{2}$ Significance level at $P<0.05$.

Abbreviation: DM, diabetes mellitus.

Table 5 Logistic regression analysis of factors related to dentists and physicians awareness

\begin{tabular}{|c|c|c|c|c|c|}
\hline \multirow[t]{2}{*}{ Model } & \multirow[t]{2}{*}{ Variables } & \multirow[t]{2}{*}{$P$-value } & \multirow[t]{2}{*}{ OR } & \multicolumn{2}{|c|}{ 95\% Cl for OR } \\
\hline & & & & Lower & Upper \\
\hline \multirow{8}{*}{$\begin{array}{l}\text { Awareness of periodontal } \\
\text { complications (Model } \chi^{2}=|3| .27 \text {, } \\
P<0.00 \mid \text { ) }\end{array}$} & Age (years) & & & & \\
\hline & $\leq 30^{\mathrm{a}}$ & & & & \\
\hline & $>30-40$ & 0.448 & 0.83 & 0.51 & 1.35 \\
\hline & $>40-50$ & $0.003^{b}$ & 2.97 & 1.44 & 6.13 \\
\hline & $>50$ & $0.045^{b}$ & 3.21 & 1.03 & 10.04 \\
\hline & Males vs female & 0.074 & 0.67 & 0.43 & 1.04 \\
\hline & Physician vs dentist & $<0.00 \mathrm{I}^{\mathrm{b}}$ & 7.82 & 5.21 & 11.79 \\
\hline & Specialist vs GP & 0.352 & 1.25 & 0.78 & 2.00 \\
\hline \multirow{8}{*}{$\begin{array}{l}\text { Practices with diabetic patients } \\
\text { (Model } \chi^{2}=35.98, P<0.00 \text { I) }\end{array}$} & Age (years) & & & & \\
\hline & $\leq 30^{\mathrm{a}}$ & & & & \\
\hline & $>30-40$ & $0.043^{b}$ & 0.63 & 0.41 & 0.99 \\
\hline & $>40-50$ & $0.039^{\mathrm{b}}$ & 2.02 & 1.04 & 3.93 \\
\hline & $>50$ & 0.178 & 2.09 & 0.72 & 6.09 \\
\hline & Males vs female & 0.136 & 1.36 & 0.91 & 2.04 \\
\hline & Physician vs dentist & $0.020^{\mathrm{b}}$ & 1.52 & 1.07 & 2.17 \\
\hline & Specialist vs GP & $0.043^{b}$ & 0.64 & 0.42 & 0.99 \\
\hline \multirow{8}{*}{$\begin{array}{l}\text { Awareness of the association } \\
\text { between periodontal disease } \\
\text { and diabetes (Model } \chi^{2}=74.02 \text {, } \\
P<0.00 \text { I) }\end{array}$} & Age (years) & & & & \\
\hline & $\leq 30^{\mathrm{a}}$ & & & & \\
\hline & $>30-40$ & $<0.00 \mathrm{I}^{\mathrm{b}}$ & 0.25 & 0.15 & 0.39 \\
\hline & $>40-50$ & $0.003^{\mathrm{b}}$ & 0.35 & 0.17 & 0.70 \\
\hline & $>50$ & $0.004^{b}$ & 0.12 & 0.03 & 0.50 \\
\hline & Males vs female & $<0.00 \mathrm{I}^{\mathrm{b}}$ & 2.35 & 1.50 & 3.68 \\
\hline & Physician vs dentist & 0.120 & 1.34 & 0.93 & 1.95 \\
\hline & Specialist vs GP & 0.970 & 0.99 & 0.63 & 1.57 \\
\hline
\end{tabular}

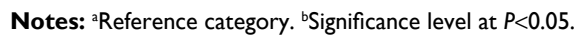

Abbreviation: OR, odds ratio. 
95\% CI: $0.42-0.99 ; P=0.043)$. Regarding the awareness of the association between periodontal diseases and diabetes, it was noted that older participants were more likely to have poor awareness about the effect of periodontal diseases and diabetes. Furthermore, male participants were more likely to have poor awareness about the effect of periodontal diseases and diabetes $(\mathrm{OR}=2.35 ; 95 \% \mathrm{CI}: 1.50-3.68 ; P<0.001)$.

\section{Discussion}

This study was conducted to establish the levels of awareness and practices among Saudi dental and medical practitioners with regard to the influence of diabetes on periodontal health and vice versa. Grounds for conducting this study were built on existing literature that comprehensively highlighted the strong association between DM and the occurrence of periodontal diseases. ${ }^{10,16-19}$ The International Diabetes Federation and World Dental Federation emphasized that there was a strong need for effective communication between practitioners and patients to foster a clear understanding of the relationship between DM and periodontal diseases. ${ }^{20}$ Improvement in awareness levels among practitioners in this regard would aid in their management of diabetic patients. However, it was seen that there was a general lack of awareness among medical and dental practitioners regarding this significant association, due to which supporting medical and dental practices could not be implemented for curbing the occurrence of periodontal diseases. Due to the lack of awareness among health care providers regarding this association, there was a corresponding lack of awareness among diabetic patients. ${ }^{14}$ As highlighted by similar studies conducted in Kuwait, there was a lower awareness level than desired among dental and medical practitioners regarding the bidirectional relationship between DM and periodontal diseases. ${ }^{14}$

This study assessed 560 medical and dental practitioners in Saudi Arabia to determine their awareness levels regarding a variety of periodontal complications associated with DM. The results of the binary regression analysis indicated that the level of awareness demonstrated by the dentists was relatively higher than that shown by the physicians. Specifically, the level of dentists' awareness in this regard was 2.254 times greater than physician awareness. Additionally, it was seen that the physicians demonstrated lower awareness levels than dentists about specific periodontal complications, such as, alveolar bone resorption, gingival bleeding, and tooth bleeding. A causal factor contributing to this difference in awareness levels may be attributed to the differences between established medical and dental curricula. It was noted by existing research that while dental curricula make oral health a focal point of study, medical curricula are primarily concerned with studying systemic conditions. ${ }^{14}$ Furthermore, dentists may not effectively communicate with the physicians with regard to the diabetic patient's oral health, due to which suitable assessments may not be made and preventative measures not be conducted. This issue was highlighted in a previous study, which reported that only $14 \%$ of the dentists in the Northeastern United States communicated with physicians regarding the diabetic patient's oral health. Furthermore, the study highlighted the inactive role of dentists in the effective management of diabetic patients. ${ }^{21}$

Although dentist awareness was higher than physician awareness, the level of awareness demonstrated by the former was still low compared to the significant influence of diabetes on periodontal health. Specifically, the results obtained demonstrated that only half of the dentists that participated in this study were acquainted with the association between $\mathrm{DM}$ and periodontal diseases. It was additionally noted that although awareness regarding the administration of prophylactic antibiotics was relatively higher in dentists than in physicians, it was still at a low level overall. These results were in line with existing research, which highlighted that $51.0 \%$ of general dentists and $29.4 \%$ of periodontists in the Northeastern United States were low performers in terms of discussions with patients about the associations between diabetes and oral health. ${ }^{22}$ Furthermore, it was highlighted by previous research conducted by Bader et $\mathrm{a}^{23}$ that there is an urgent requirement for general dentists to improve their abilities regarding the recognition of diabetes as a high-risk indicator for periodontal diseases. Additionally, it was seen that the female dentists, who participated in this study, demonstrated relatively greater levels of awareness than their male counterparts. These results were in accordance with a study by Forbes et al, ${ }^{24}$ which demonstrated that female dentists were more likely than male dentists to refer diabetic patients for monitoring blood glucose, adjusting the frequency of dental visits and discussing how periodontal therapy affects metabolic control. The level of discussion and active management was significantly associated with the number of consultations with dental and medical specialists.

The primary area of concern noted by this study was the lack of effective collaboration between general dentists, dental specialists, and medical practitioners. A study by Lee et $\mathrm{a}^{25}$ highlighted the presence of a negative attitude among general dentists regarding periodontal referrals. The study discussed the presence of a directly proportional relationship between positive dentist perceptions regarding their own periodontal education and the level of their conversations about 
considering bone loss percentages as a basis for referral. Furthermore, the study highlighted the existence of a directly proportional relationship between positive dentist perceptions regarding their periodontal education and the frequency of their use of systemic antibiotics in the treatment of periodontal diseases. Since general dentists are considered to be the primary referral source of patients with advanced periodontal conditions, it is vital that periodontists educate these general practitioners about the risk of developing periodontal diseases in diabetic patients. Additionally, a questionnaire-based study by Ward et $\mathrm{al}^{26}$ examined the knowledge and attitudes of 137 primary care nurse practitioners regarding the periodontal disease-systemic link. The results obtained indicated that nurse practitioners were significantly more likely to screen patients when they experienced positive emotions regarding their training and education. Furthermore, the study suggested that these nurse practitioners were more likely to screen patients when they believed it was within their scope of practice to screen for periodontal diseases, and when they had control over the establishment of office protocols. These results support the importance of interprofessional and collaborative education among the medical, nursing, and dental professions. $^{27}$

As discussed earlier, the ineffective dissemination of awareness pertaining to DM and periodontal diseases is a significant concern that needs to be addressed so that the awareness levels among medical and dental practitioners may be increased. In order to boost awareness levels regarding DM and periodontal complications, educational programs may be utilized for the health care providers. The results obtained additionally noted the prevalence of poor awareness among older physicians and dental practitioners. Therefore, it is essential that educational programs be devised so as to cater to enhancing the awareness levels of these older health care providers. Furthermore, an integrated practice structure should be established for the effective management of diabetic patients through instigating open channels of communication between dental and medical practitioners. In this way, suitable assessments of diabetic patient conditions may be made and preventative measures may be taken to curb the occurrence of periodontal diseases.

Additionally, it is important to consider that a large number of individuals may be unaware that they are afflicted with diabetes and may not receive a diagnosis until the development of complications, such as periodontal diseases. However, individuals with a self-reported family history of diabetes, hypertension, high cholesterol levels, and clinical evidence of periodontal diseases bear a probability of
$27 \%-53 \%$ of having undiagnosed diabetes. ${ }^{28}$ Therefore, it is essential for dental and medical organizations to collaborate in screening for unidentified diabetes. Dentists, physicians, and other health care providers should provide accurate information to diabetic patients regarding the association between diabetes and oral health and encourage them to obtain oral health examinations and undergo the required treatments. This would act as a preventative measure against the development of periodontal diseases that arise as a result of diabetes.

The results of present study have helped in devising effective educational programs and integrative clinical practices to increase the level of awareness demonstrated by these health care providers and contribute to a culture of intellectual growth regarding this bidirectional relationship between DM and the onset of periodontal diseases. However, this study was based on self-reported data and utilized a low study sample set. Further studies should be conducted with a larger study sample set to obtain concrete results. Moreover, future studies are needed for demonstrating superior awareness levels to physicians as their awareness levels investigated in this study were still low as compared to the impact of DM on periodontal health.

\section{Conclusion}

This study conducted an evaluation of awareness levels regarding the relationship between DM and the onset of periodontal diseases among dental and medical practitioners in Saudi Arabia. It was seen that the awareness regarding specific periodontal complications associated with diabetes was lower with regard to this study sample. Although dentists demonstrated superior awareness levels compared with physicians, their awareness levels were still low as compared to the impact of DM on periodontal health. It is essential for dental and medical practitioners to comprehend the strong association between DM and periodontal diseases to be able to provide appropriate clinical evaluations and preventative measures against the occurrence of such complications in diabetic patients. Furthermore, educational programs should be conducted to raise the awareness levels of health care providers in this regard for the effective management of diabetic patients. Integrated clinical practices should be implemented with the aim of initiating open communication between dental and medical practitioners in this regard.

\section{Acknowledgment}

The author is very thankful to all the associated personnel in any reference that contributed in/for the purpose of this research. 


\section{Disclosure}

The author reports no conflicts of interest in this work.

\section{References}

1. Centers for Disease Control and Prevention, National Center for Health Statistics. National Health and Examination Survey (NHANES); 1999-2002. Atlanta, GA: Centers for Disease Control and Prevention. Available from: http://www.cdc.gov/nchs/nhanes.htm. Accessed December 28, 2006.

2. Centers for Disease Control and Prevention (CDC). Prevalence of diabetes and impaired fasting glucose in adults--United States, 1999-2000. MMWR Morb Mortal Wkly Rep. 2003;52(35):833-837.

3. Cowie CC, Rust KF, Byrd-Holt DD, et al. Prevalence of diabetes and impaired fasting glucose in adults in the U.S. population: National Health And Nutrition Examination Survey 1999-2002. Diabetes Care. 2006;29(6):1263-1268.

4. Harris MI. Diabetes in America: epidemiology and scope of the problem. Diabetes Care. 1998;21 Suppl 3:C11-C14.

5. Harris MI, Flegal KM, Cowie CC, et al. Prevalence of diabetes, impaired fasting glucose, and impaired glucose tolerance in U.S. adults. The Third National Health and Nutrition Examination Survey, 1988-1994. Diabetes Care. 1998;21(4):518-524.

6. US Census Bureau. Accessing Census Bureau Population Estimates. Available from: https://www.census.gov/content/dam/Census/data/ training-workshops/recorded-webinars/pop-estimates6-22-16.pdf. Accessed September, 22, 2018.

7. Wild S, Roglic G, Green A, Sicree R, King H. Global prevalence of diabetes: estimates for the year 2000 and projections for 2030. Diabetes Care. 2004;27(5):1047-1053.

8. Al-Nozha MM, Al-Maatouq MA, Al-Mazrou YY, et al. Diabetes mellitus in Saudi Arabia. Saudi Med J. 2004;25(11):1603-1610.

9. Mealey BL, Oates TW, American Academy of Periodontology. Diabetes mellitus and periodontal diseases. J Periodontol. 2006;77(8):1289-1303.

10. Taylor GW. Bidirectional interrelationships between diabetes and periodontal diseases: an epidemiologic perspective. Ann Periodontol. 2001;6(1):99-112.

11. Boehm TK, Scannapieco FA. The epidemiology, consequences and management of periodontal disease in older adults. J Am Dent Assoc. 2007;138(Suppl):S26-S33.

12. Grossi SG, Zambon JJ, Ho AW, et al. Assessment of risk for periodontal disease. I. Risk indicators for attachment loss. J Periodontol. 1994;65(3):260-267.

13. Johnson NW, Griffiths GS, Wilton JM, et al. Detection of high-risk groups and individuals for periodontal diseases. Evidence for the existence of high-risk groups and individuals and approaches to their detection. J Clin Periodontol. 1988;15(5):276-282.
14. Al-Khabbaz AK, Al-Shammari KF, Al-Saleh NA. Knowledge about the association between periodontal diseases and diabetes mellitus: contrasting dentists and physicians. J Periodontol. 2011;82(3):360-366.

15. Bahammam MA. Periodontal health and diabetes awareness among Saudi diabetes patients. Patient Prefer Adherence. 2015;9:225-233.

16. Allen EM, Matthews JB, O’ Halloran DJ, Griffiths HR, Chapple IL. Oxidative and inflammatory status in Type 2 diabetes patients with periodontitis. J Clin Periodontol. 2011;38(10):894-901.

17. Choi YH, Mckeown RE, Mayer-Davis EJ, Liese AD, Song KB, Merchant AT. Association between periodontitis and impaired fasting glucose and diabetes. Diabetes Care. 2011;34(2):381-386.

18. Kuo LC, Polson AM, Kang T. Associations between periodontal diseases and systemic diseases: a review of the inter-relationships and interactions with diabetes, respiratory diseases, cardiovascular diseases and osteoporosis. Public Health. 2008;122(4):417-433.

19. Nishimura F, Iwamoto Y, Mineshiba J, Shimizu A, Soga Y, Murayama Y. Periodontal disease and diabetes mellitus: the role of tumor necrosis factor-alpha in a 2-way relationship. J Periodontol. 2003;74(1):97-102.

20. World Dental Federation. Oral Health Observatory special symposium to be held at FDI World Dental Congress. Available from: https:// www.fdiworlddental.org/news/20180806/oral-health-observatoryspecial-symposium-to-be-held-at-fdi-world-dental-congress. Accessed September, 22, 2018.

21. Kunzel C, Lalla E, Lamster IB. Management of the patient who smokes and the diabetic patient in the dental office. J Periodontol. 2006;77(3):331-340.

22. Kunzel C, Lalla E, Lamster I. Dentists' management of the diabetic patient: contrasting generalists and specialists. Am J Public Health. 2007;97(4): 725-730.

23. Bader JD, Shugars DA, Kennedy JE, Hayden WJ, Baker S. A pilot study of risk-based prevention in private practice. JAm Dent Assoc. 2003;134(9): 1195-1202.

24. Forbes K, Thomson WM, Kunzel C, Lalla E, Lamster IB. Management of patients with diabetes by general dentists in New Zealand. J Periodontol. 2008;79(8):1401-1408.

25. Lee JH, Bennett DE, Richards PS, Inglehart MR. Periodontal referral patterns of general dentists: lessons for dental education. J Dent Educ. 2009;73(2):199-210.

26. Ward AS, Cobb CM, Kelly PJ, Walker MP, Williams KB. Application of the theory of planned behavior to nurse practitioners' understanding of the periodontal disease-systemic link. J Periodontol. 2010;81(12):1805-1813.

27. Mann KV, Mcfetridge-Durdle J, Martin-Misener R, et al. Interprofessional education for students of the health professions: the "Seamless Care" model. J Interprof Care. 2009;23(3):224-233.

28. Borrell LN, Kunzel C, Lamster I, Lalla E. Diabetes in the dental office: using NHANES III to estimate the probability of undiagnosed disease. J Periodontal Res. 2007;42(6):559-565.
Journal of Multidisciplinary Healthcare

\section{Publish your work in this journal}

The Journal of Multidisciplinary Healthcare is an international, peerreviewed open-access journal that aims to represent and publish research in healthcare areas delivered by practitioners of different disciplines. This includes studies and reviews conducted by multidisciplinary teams as well as research which evaluates the results or conduct of such teams or health care processes in general. The journal covers a very wide range of areas and welcomes submissions from practitioners at all levels, from all over the world. The manuscript management system is completely online and includes a very quick and fair peer-review system. Visit http://www.dovepress.com/ testimonials.php to read real quotes from published authors. 